www.jmscr.igmpublication.org

Impact Factor 5.84

Index Copernicus Value: 71.58

ISSN (e)-2347-176x ISSN (p) 2455-0450

crossref DOI: _https://dx.doi.org/10.18535/jmscr/v5i9.162

\title{
Assessment of Serum Uric Acid Levels in Acute Ischemic Stroke
}

\author{
Authors \\ Dr Sheik Mohammed Raja. E. ${ }^{* 1}$, Dr M. Ramakrishna Rao ${ }^{2}$, Dr Tanzeem.S \\ ${ }^{* 1,3}$ Post Graduate, Department of General Medicine, Rajah Muthiah Medical College and Hospital, \\ Annamalai University, Annamalai Nagar - 608002 \\ ${ }^{2}$ Professor, Department of General Medicine, Rajah Muthiah Medical College and Hospital, Annamalai \\ University, Annamalai Nagar - 608002 \\ Corresponding Author \\ Dr Sheik Mohammed Raja. E.
}

Post Graduate, Department of General Medicine, Rajah Muthiah Medical College and Hospital, Annamalai

University, Annamalai Nagar - 608002

\begin{abstract}
The role of serum uric acid (SUA) levels as an independent risk factor for vascular disease has been questioned for decades. Recent studies suggest that the elevated SUA levels may predict an increased risk for cerebrovascular (CV) events including stroke. If the levels of other antioxidants like ascorbic acid are low, SUA can work as pro-oxidant. Various studies showed that elevated SUA levels can result in endothelial dysfunction which can lead to vascular disease. An association between SUA and inflammatory markers has also been discovered.

Keywords: SUA, Ischemic stroke.
\end{abstract}

\section{Introduction}

Stroke is the third most common cause of death. Cerebrovascular disease is estimated to account for 7.8 million deaths yearly throughout the world and represents about $13 \%$ of all causes of death. ${ }^{1}$ In humans, most abundant anti oxidant is uric acid and it is the most important of all free radical scavengers in plasma and serve as a protective role by preventing lipid peroxidation. ${ }^{2}$ During acute oxidative stress and ischemia local UA concentrations increases in organs and vascular bed, which helps in protection against free radical activity. $^{3}$
The study was done to estimate and to identify the correlation of serum uric acid level in patients with acute ischemic stroke.

\section{Methodology}

This study includes 100 patients admitted to RMMCH, Chidambaram with acute ischemic stroke within $24 \mathrm{hrs}$ of onset of symptoms.

Patients with previous history of TIA, CVA, presented after $24 \mathrm{hrs}$ of onset of symptoms, who are on thiazide diuretics, known case of gout $\&$ chronic renal failure, whose CT scan shows hemorrhage or other space occupying lesion other than infarct were excluded from study. 


\section{JMSCR Vol||05||Issue||09||Page 28335-28337||September}

A detailed history and thorough clinical examination was carried out. A part from routine investigations estimation of serum uric acid was carried out within $24 \mathrm{hrs}$ onset of symptoms of acute ischemic stroke.

\section{Observation and Results}

The age of patients in present study ranged from 41 years to 84 years with a mean age of 59.8 years, Male to female ratio being 1:1. Majority of stroke population are between 50 to 69 years $(63 \%$ of population). The elderly population above 70 years old constitutes $19 \%$.

Age wise distribution of uric acid is found statistically significant. As age advances uric acid also rises. This significance is maintained even when Male and Female population is considered separately.

Table 1: Uric Acid (mg/dl)

\begin{tabular}{|l|c|c|c|c|}
\hline \multirow{2}{*}{ Uric Acid } & \multicolumn{4}{|c|}{ Cases } \\
\cline { 2 - 5 } & \multicolumn{2}{|c|}{ Males } & \multicolumn{2}{c|}{ Females } \\
\hline (mg/dl) & No. & $\%$ & No. & $\%$ \\
\hline Less than 5 & 25 & 50 & 24 & 48 \\
\hline $5-6.9$ & 13 & 26 & 13 & 26 \\
\hline 7 \& Above & 12 & 24 & 13 & 26 \\
\hline Total & 50 & 100 & 50 & 100 \\
\hline Mean & 5.42 & \multicolumn{2}{c|}{5.49} \\
\hline S.D & \multicolumn{2}{|c|}{1.87} & \multicolumn{3}{c|}{1.52} \\
\hline \multirow{2}{*}{ 'p' } & \multicolumn{4}{|c|}{ Not significant } \\
\cline { 2 - 5 } & \multicolumn{5}{c}{} \\
\hline
\end{tabular}

Mean uric acid level in males is $5.42 \mathrm{mg} / \mathrm{dl}$ and in females it is $5.49 \mathrm{mg} / \mathrm{dl}$.

Table 2: Age and uric Acid according to Sex

\begin{tabular}{|l|l|l|l|c|}
\hline \multirow{2}{*}{ Age group } & \multicolumn{4}{|c|}{ Uric Acid } \\
\cline { 2 - 5 } & \multicolumn{2}{|c|}{ Males } & \multicolumn{2}{c|}{ Females } \\
\cline { 2 - 5 } & Mean & S.D. & Mean & S.D. \\
\hline $40-49$ & 4.30 & 1.821 & 4.48 & 0.69 \\
\hline $50-59$ & 4.91 & 1.54 & 4.91 & 1.30 \\
\hline $60-69$ & 5.62 & 1.66 & 5.54 & 1.50 \\
\hline $70-79$ & 6.88 & 2.21 & 7.02 & 1.54 \\
\hline $80 \&$ above & 8.40 & 0.00 & 5.60 & 1.50 \\
\hline 'p' & \multicolumn{2}{|c|}{0.008} & \multicolumn{2}{c|}{0.005} \\
\hline \multicolumn{4}{|c|}{ ignificant } & \multicolumn{2}{c|}{ Significant } \\
\hline
\end{tabular}

The mean uric acid value for $40-49$ yrs group is $4.46 \mathrm{mg} / \mathrm{dl}$ while the elderly age group of above $70 \mathrm{yrs}$ has the mean value $6.84 \mathrm{mg} / \mathrm{dl}$.
Graph - I: Age and Uric Acid

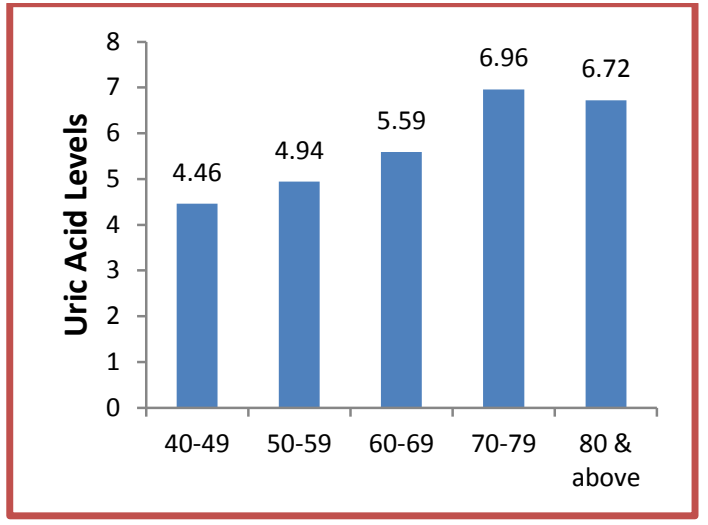

There is no statistically significant association is found in this study between sex and uric acid. The mean uric acid level among male population is $5.42 \mathrm{mg} / \mathrm{dl}$ and among female population it is $5.49 \mathrm{mg} / \mathrm{dl}$.

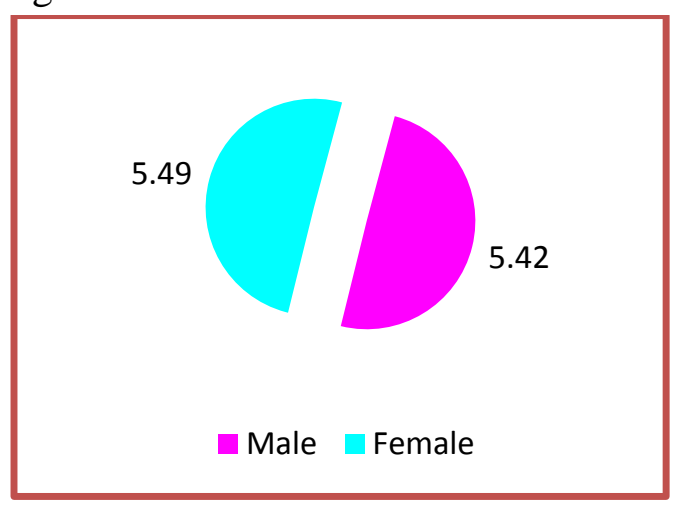

\section{Discussion}

The mortality rate of stroke in the acute phase is as high as $20 \%$. Stroke remains an important cause of morbidity and long term disability; Uric acid is a final end product of purine metabolism. Long been considered only in the pathogenesis of gout and uric acid stones. Its role in the pathogenesis of hypertension, cardiovascular, cerebrovascular and its anti-oxidant functions events are been considered of late. Serum uric acid levels in vascular events have proven its prognostic significance in recent studies. Uric acid is also been considered as a marker for atherosclerosis. An association between SUA and inflammatory markers has also been discovered ${ }^{4,5}$. In a study by Iribarreen, Folsom and Eckfeldt et al., ${ }^{6}$ found a positive correlation between uric acid levels and asymptomatic carotid atherosclerosis. Uric acid level can be used to predict future cerebrovascular events. 
A study by Hozawa A. Folsom et al. ${ }^{7}$ also showed increased uric acid levels in patients with ischemic stroke.

In a study by Longo Mbenza, et al. ${ }^{8}$ among African patients found that uric acid levels were elevated among stroke patients.

The serum uric acid level was compared between male and female patients. Mean uric acid levels in males $5.42 \mathrm{mg} / \mathrm{dl}$ and $5.49 \mathrm{mg} / \mathrm{dl}$ in females. No statistically significant association found between gender and uric acid. But in a study by Chamorro et al. ${ }^{9}$ serum uric acid levels were found to be higher in males.

Age is the most common non-modifiable risk factor for the development of stroke. The mean age of the male population is 59.08yrs and of the female population is 60.5 yrs. Age wise distribution of uric acid is found statistically significant and the association was maintained even when both sexes are considered separately.Our study is consistent with Milinois et al who found elevated SUA in individuals older than 70 years. ${ }^{10}$

\section{Conclusion}

Elevated SUA is strongly associated with an increased risk for the development of acute ischemic stroke in this study population. The association between elevated SUA and ischemic stroke may need to be considered especially when treating elderly patients. Uric acid has been considered as a surrogate biochemical markers of oxidative stress in acute ischemic stroke. Elevated uric acid among stroke patients concurred with previous publication. It is also suggested that further studies are required to assess whether lowering of SUA level with drugs can actually reduce the risk of ischemic stroke.

\section{References}

1. Adam and Victor's principles of Neurology $10^{\text {th }}$ edition; Chapter 34; page 778-792

2. Squadrito GL, Cueto R, Splenser AE, Valavanidis A, Zhang H, Uppu RM, et al. Reaction of uric acid with peroxynitrite and implications for the mechanism of neuroprotection by uric acid. Arch Biochem Biophys 2000; 376: 333- 337.

3. Nieto FJ, Iribarren C, Gross MD, Comstock GW, Cutler RG. Uric acid and serum antioxidant capacity: a reaction to atherosclerosis? Atherosclerosis 2000; 148:131-139.

4. Adauff GW, Atkins E, Malawista SE. The fever of gout; urate crystals activate endogenous pyrogen production from human and rabbit mononuclear phagocytes. Trans Assoc Am Physician. 1983: 96: 234-245.

5. Kondo N, Nomura $M$, Nakaya $Y$, Itos $S$, Phfuro T. Association of inflammatory marker and highly sensitive CRP with aerobic exercise capacity, maximum oxygen uptake and insulin resistance in healthy middle aged volunteers; Circ J;2005; 69(4); 452-457.

6. Iribarren C, Folsom AR, Eckfeldt JH, MC Govern PG, Nieho FJ. Correlates of uric acid and its association with asymptomatic carotid atherosclerosis; the ARIC study; Atherosclerosis Risk in communities. Stroke, 1999; 29: 635-639.

7. Hozawa, A. Folson AR. Uric acid is an independent predictor of ischemic stroke among subjects not using diuretics. Atherosclerosis, 2006, 187(2): 401-407.

8. Longo Mbenza B, Luila EL, Mbete P, Vita EK. Is hyperuricemia a risk factor of stroke and coronary heart disease among Africans. Int. J. Cardiol., 1999, 71(1): 17-22.

9. Chamorro A, Obach V, Cervera A, Revilla M, Deulofeu R, Aponte JH. Prognostic significance of uric acid serum concentration in patients with acute ischemic stroke. Stroke 2002; 33: 1048- 1052 .

10. Milionis HJ, Kalantzi KJ, Goudevenos JA, Seferiadis K, Mikhailidis DP, Elisaf MS. Serum uric acid levels and risk for acute ischemic non-embolic stroke in elderly subjects. J Intern Med 2005; 258: 435 - 441. 